\title{
Genetic Characterisation and Diversity Assessment of Potato Genotypes Using SSR Markers
}

\author{
Prossy Namugga $^{1,2}$, Julia Sibiya ${ }^{1}$, Rob Melis $^{1} \&$ Alex Barekye ${ }^{2}$ \\ ${ }^{1}$ African Centre for Crop Improvement, School of Agricultural, Earth and Environmental Sciences, University of \\ KwaZulu-Natal, Pietermaritzburg, South Africa \\ 2 National Agricultural Research Organisation (NARO), Kachwekano Zonal Agricultural Research and \\ Development Institute, Kabale, Uganda \\ Correspondence: Prossy Namugga, African Centre for Crop Improvement, School of Agricultural, Earth and \\ Environmental Sciences, University of Kwa Zulu-Natal, Private Bag X01, Scottsville 3209, Pietermaritzburg, \\ South Africa. Tel: 27-2567-8236-1597. E-mail: namuggak@gmail.com
}

Received: May 8, 2017

doi:10.5539/jas.v9n8p99
Accepted: June 16, $2017 \quad$ Online Published: July 15, 2017

URL: https://doi.org/10.5539/jas.v9n8p99

\begin{abstract}
Information on diversity of genetic materials is vital for choosing parents in a breeding program. The objective of the study was to determine the pattern and level of genetic diversity among the selected 20 tetraploid potato genotypes using 16 SSR markers to identify suitable parents for breeding purposes. The microsatellites showed considerable variation among genotypes and sixty four alleles were amplified by the 16 primer pairs. The number of polymorphic alleles per locus ranged from 2 to 8 with an average of 3.9. The highest number of null alleles was observed was six for genotype Nakpot1. The overall size of the amplified product varied from $48 \mathrm{bp}$ (marker STI0023) to $309 \mathrm{bp}$ (marker STM5121). PIC values ranged from 0.0948 to 0.7832 , with an average of 0.4307 per locus. Heterozygosity values ranged from 0.0997 to 0.805 with an average of 0.466919 . Significant positive linear correlations were observed between PIC values and number of alleles $(r=0.905)$; and heterozygosity and number of alleles $(r=0.8659)$ at $p<0.001$. Cluster analysis separated the genotypes into three different groups. The genetic distance between clones ranged from 1 to 5.7. Cruza had the highest genetic distance while the shortest genetic distance was observed between 396026.103 and 396034.104. The microsatellites used in this study provided useful information regarding the variability of the tested genotypes and their selection for breeding purposes.
\end{abstract}

Keywords: genetic variation, polymorphism, clustering, heterozygosity, microsatellites, Uganda

\section{Introduction}

The cultivated potato, Solanum tuberosum, is a highly heterozygous autotetraploid species $(2 n=4 x=48)$, with a genome size of $844 \mathrm{Mb}$ (Muthoni et al., 2012). It is primarily outcrossing and experiences severe inbreeding depression (Park et al., 2009). The crop displays tetrasomic inheritance which results into increased number of progeny classes and allelic dosage (Hirut, 2015).

Selection of parental materials and understanding of appropriate parents to be used for a particular mating design are key in breeding (Acquaah, 2007). A number of approaches have been used by breeders to select the best parents and cross- combinations. These include: combining ability effects, use of mid-parent values, progeny tests, estimated breeding values, and genetic diversity (Gopal, 2015). However, to obtain reliable results with the intricacies of potato genetics and inheritance pattern, various methods should be combined to aid in the selection of parents (Sharma and Nandineni, 2014). While a narrow genetic base would result into inbreeding depression as a consequence of accumulation of deleterious alleles in a population (Gopal, 2014), high level of genetic diversity among potato genotypes possessing different desirable traits is important for crop improvement. This is because selection of parents based on genetic diversity will maximize heterozygosity, broaden the genetic base and produce heterotic progenies (Sun et al., 2003).

Diversity assessment can be achieved through the use of phenotypic information, pedigree, biochemical and molecular markers (Govindaraj et al., 2015). The use of molecular markers is the most reliable method of assessing genetic diversity because they are: stable, independent of the environment and not affected by the developmental 
stage of the plant, pleiotropic, and epistatic effects. Different molecular markers have been used to estimate genetic diversity in plants and animals. These comprise of- random amplified polymorphic DNAs (RAPDs), restriction fragment length polymorphism (RFLPs), amplified fragment length polymorphism (AFLP), microsatellites or simple sequence repeats (SSRs), and single nucleotide polymorphisms (SNPs) among others. With RAPDs, the primers are commercially available and do not require prior information of the target DNA sequence. However, this type of marker does not easily demonstrate Mendelian inheritance of the loci and unable to differentiate between homozygotes and heterozygote. The key strength of RFLP markers is that they are codominant markers and relatively easy to score because of the large size difference. The major shortcoming of these markers is that they either require sequence information or probes. This makes it difficult and time-consuming to develop markers for species lacking known molecular information (Liu \& Cordes, 2004). AFLPs are reliable but expensive, labour intensive with long assays (Tiwari et al., 2013).

Microsatellites are therefore the most commonly used markers due to their strong molecular approach to genetic diversity studies. Microsatellites are highly polymorphic, abundant, co-dominant and can be used to detect heterozygosity. They are simple to use, provide high genetic information and are highly reproducible (Muthoni et al., 2014). Additionally, the SSRs have the capacity to reflect ploidy status with the high heterozygosity of the tetraploid potatoes. It is against this back ground that SSR markers were used in this study to determine the genetic relationships among 20 potato clones with variable resistance to late blight.

\section{Materials and Methods}

\subsection{Plant Materials}

The test materials comprised of twenty potato genotypes. These were eleven commercial varieties from the national potato programme, six farmer varieties and three CIP clones of which two were released as varieties in Uganda and two crosses from the national potato research centre with variable resistance to late blight (Table 1).

Table 1. List of the twenty potato genotypes and their sources

\begin{tabular}{|c|c|c|c|c|c|}
\hline Entry & Clones & Source & Entry & Clones & Source \\
\hline 1 & Cruza & NARO & 11 & NKRI59.41 & NARO \\
\hline 2 & Kabera & Farmer & 12 & Petero & Farmer \\
\hline 3 & Kachpot1 & NARO & 13 & Rwangume & NARO \\
\hline 4 & Kimuri & Farmer & 14 & Rwashaki & NARO \\
\hline 5 & Kinigi & Rwanda & 15 & Rutuku & NARO \\
\hline 6 & Mabondo & Farmer & 16 & Shutama & Farmer \\
\hline 7 & Mbubamagara & Farmer & 17 & Victoria & NARO \\
\hline 8 & Nakpot1 & NARO & 18 & 396026.103 & CIP \\
\hline 9 & Nakpot5 & NARO & 19 & 396034.103 & CIP \\
\hline 10 & NKRK19.10 & NARO & 20 & 396038.107 & CIP \\
\hline
\end{tabular}

Note. $\mathrm{CIP}=$ International Potato Centre, $\mathrm{NARO}=$ National Agricultural Research Organisation.

\subsection{DNA Extraction and SSR Amplification}

Fresh young leaves were picked from one month old plants in the field for DNA extraction. DNA was obtained using fast technology for analysis of nucleic acids (Whatman FTA cards) following modified protocols of FTA paper technology (Mbogori et al., 2006). One FTA classic card measures $750 \times 130 \mathrm{~mm}$ and each was labelled prior to the day of sampling. Ten plants were sampled from each clone and one leaf per plant. Each sampled leaf was immediately placed on the FTA card and pressed using a pair of pliers until both sides of the FTA paper were with the sap. Ethanol $70 \%$ was used to clean the pliers between samples to prevent cross contamination. The FTA card was then dried at room temperature for 2-5 hours, after which packed and sent to INCOTEC South Africa (pty) Ltd. for laboratory analysis. DNA was extracted from FTA cards and sixteen microsatellite markers were used. These were: STM2013, STM1104, STM1049, STM0037, STI0012, STI0023, STI0030, STI0036, STI0032, STWAX-2, STI046, STI031, STM0030, STM1031, STM5121, STM0019a and STPoA58.

\subsection{Data Analysis}

PCR products were fluorescently labelled and separated by capillary electrophoresis on an ABI 313oxl automatic sequencer (Applied Biosystems, Johannesburg, South Africa). The analysis was performed using GeneMapper 
4.1. The SSR marker alleles were scored for presence or absence of the band for all the 20 potato genotypes. Each amplified fragment was considered as one locus. The GGT 2.0 program (Van Berloo, 2008) was used to calculate the Euclidian distances between bulked samples and the matrix of the genetic distances was used to create a UPGMA dendogram. The genetic similarity matrix of potato genotypes was calculated using the Jaccard's coefficient (Anderberg, 1973). Genetic diversity parameters, such as the total number of alleles per locus, expected heterozygosity and polymorphic information content (PIC) were determined. The PIC, which is a measure of allelic diversity, was calculated, based on the equation: $\mathrm{PIC}=1-\Sigma\left(\mathrm{pi}^{2}\right)$, where pi is the frequency of $\mathrm{i}^{\text {th }}$ allele in the accessions. Pearson's correlation coefficients showing pair-wise association between PIC, He and number of alleles were calculated using Genstat statistical package, 14th edition (Payne et al., 2011).

\section{Results}

\subsection{Allelic Information}

The twenty potato genotypes used in this study were uniquely differentiated by the 16 SSR markers (Table 2). Markers differed significantly in their ability to establish variability amongst the clones. Particular markers generated several alleles while others produced a few. The 16 SSR primers identified a total of 64 alleles among the test clones. The number of polymorphic alleles scored across SSR loci ranged from 2 to 8 with an average of 3.9. The number of polymorphic alleles above average was obtained from only $50 \%$ of the markers. Null alleles were observed for some markers and the genotype with the highest frequency recorded was NAKPOT1. With this genotype $38 \%$ (6) of the markers failed to yield detectable amplification. This was followed by genotype Mbubamagara with $31 \%$ of null alleles. The overall size of the amplified product varied from 48 bp (marker STI0023) to $309 \mathrm{bp}$ (marker STM5121).

Heterozygosity values (He), the measure of allelic diversity at a locus ranged from 0.099 to 0.805 with an average of 0.467 . The level of polymorphism among the potato clones was evaluated by calculating PIC values for each of the 16 SSR loci which differed significantly from locus to another. These ranged from 0.095 for markers STI002 to 0.783 for STI031, with an average value of 0.431 per locus (Table 3). However, markers STI0023, STM1049, STM0037 and STM5121 had a very limited ability to detect differences among the potato genotypes as shown by their low PIC values. The marker with the highest PIC value (0.805) was STI031. There was significant positive linear correlations between PIC values and number of alleles; and heterozygosity and number of alleles at the SSR locus $(r=0.905$ and $r=0.866 ; p<0.001)$ respectively (Table 2 ).

Table 2. Correlation coefficients showing the relationship between polymorphic information content, heterozygosity and number of alleles

\begin{tabular}{lll}
\hline & He & Number of alleles \\
\hline He & - & \\
Number of alleles & $0.844^{* * * *}$ & - \\
PIC & $0.994^{* * *}$ & $0.891^{* * *}$ \\
\hline
\end{tabular}

Note. $^{* * *}=$ significant at $\mathrm{P} \leq 0.001, \mathrm{PIC}=$ polymorphic information content (PIC), He: heterozygosity.

\subsection{Cluster Analysis of Potato Clones}

The dendrogram was constructed using UPGMA clustering algorithm based on SSR data matrices and grouped the potato clones into three major clusters (Figure 1). The first cluster consisted of ten clones seven of which are commonly grown varieties bred by the International Potato Center (CIP) and released in Uganda. The two lines in this cluster (NKRK19.10 and NKRN59.41) are crosses from potato genotypes (Rutuku $\times$ Kackpot1 and Rutuku $\times$ NakPot5) respectively. The second cluster consisted of seven clones, four of them (Kabera, Shutama, Mbumbamagara and Kimuli) are farmers' varieties while the rest were from population B3C2 obtained from CIP. And the third cluster consisted of Kachpot1, Mabondo and NakPot1. Shutama was the least genetically related to other clones (1.9) followed by Kabera, Kachpot1 and Mbumbamagara. The most closely related varieties were 396026.103 and 396034.104. Varieties Shutama and Mbumbamagara, are taken to be the same by farmers but given different names in the potato growing districts of Kisoro and Kabale respectively. However, the results of this study revealed a genetic difference between the two with genetic distances of 1.9 and 1.6 respectively albeit belonging to the same cluster. There was a close relationship between the genetic clustering and the phenotypic characteristics of the studied genotypes. For example, 57\% of the susceptible genotypes belonged to cluster two and all these take between $70-90$ days to maturity. Additionally, $86 \%$ of the moderately late blight resistant and 
high yielding genotypes were in cluster one. The genetic distance between clones ranged from 1 to 5.7 (Table 4 ). The highest range was found with Cruza indicating its less relatedness to other clones studied. The shortest genetic distance between 396026.103 and 396034.104 (1.0) could be due to the fact that both are from population $\mathrm{B} 2 \mathrm{C} 3$ and possibly selections from a single cross.

Table 3. SSR repeat types and primer sequences, allelic information, heterozygosity and PIC values of 16 SSR loci used for genotyping

\begin{tabular}{|c|c|c|c|c|c|c|c|c|}
\hline No & $\begin{array}{l}\text { Marker } \\
\text { name }\end{array}$ & Repeat & $\begin{array}{l}\text { Primer sequences }\left(5^{`}-3^{`}\right) \\
\text { Forward-Reverse }\end{array}$ & $\begin{array}{l}\text { Allele size } \\
\text { (range bp) }\end{array}$ & $\begin{array}{l}\text { No of } \\
\text { alleles }\end{array}$ & $\mathrm{He}$ & PIC & $\begin{array}{l}\text { PGI } \\
\text { Kit }\end{array}$ \\
\hline 1 & STM2013 & (TCTA) 6 & $\begin{array}{l}\text { TTCGGAATTACCCTCTGCC } \\
\text { AAAAAAAGAACGCGCACG }\end{array}$ & $164-166$ & 2 & 0.420 & 0.338 & No \\
\hline 2 & STM1104 & $(\mathrm{TCT}) 5$ & $\begin{array}{l}\text { TGATTCTCTTGCCTACTGTAATCG } \\
\text { CAAAGTGGTGTGAAGCTGTGA }\end{array}$ & $185-189$ & 4 & 0.565 & 0.509 & Yes \\
\hline 3 & STM1049 & (ATA) 6 & $\begin{array}{l}\text { CTACCAGTTTGTTGATTGTGGTG } \\
\text { AGGGACTTTAATTTGTTGGACG }\end{array}$ & $201-210$ & 3 & 0.277 & 0.257 & No \\
\hline 4 & STM0037 & $\begin{array}{l}\text { (TC)5(AC)6AA } \\
\text { (AC)7(AT) } 4\end{array}$ & $\begin{array}{l}\text { AATTTAACTTAGAAGATTAGTC } \\
\text { TCATTTGGTTGGGTATGATA }\end{array}$ & $89-96$ & 3 & 0.265 & 0.247 & Yes \\
\hline 5 & STI0012 & $(\mathrm{ATT}) \mathrm{n}$ & $\begin{array}{l}\text { GAAGCGACTTCCAAAATCAGAA } \\
\text { AAGGGAGGAATAGAAACCAAAA }\end{array}$ & $185-191$ & 3 & 0.602 & 0.531 & Yes \\
\hline 6 & STI0023 & $(\mathrm{CAG}) \mathrm{n}$ & $\begin{array}{l}\text { GCGAATGACAGGACAAGAGG } \\
\text { TGCCACTGCTACCATAACCA }\end{array}$ & $48-49$ & 2 & 0.099 & 0.095 & No \\
\hline 7 & STI0030 & $(\mathrm{ATT}) \mathrm{n}$ & $\begin{array}{l}\text { TTGACCCTCCAACTATAGATTCTTC } \\
\text { TGACAACTTTAAAGCATATGTCAGC }\end{array}$ & $53-54$ & 2 & 0.388 & 0.313 & Yes \\
\hline 8 & STI0036 & (AC)n(TC)imp & $\begin{array}{l}\text { GGACTGGCTGACCATGAACT } \\
\text { TTACAGGAAATGCAAACTTCG }\end{array}$ & $134-147$ & 4 & 0.582 & 0.544 & No \\
\hline 9 & STI0032 & $(\mathrm{GGA}) \mathrm{n}$ & $\begin{array}{l}\text { TGGGAAGAATCCTGAAATGG } \\
\text { TGCTCTACCAATTAACGGCA }\end{array}$ & $128-144$ & 6 & 0.760 & 0.723 & Yes \\
\hline 10 & STWAX-2 & (ACTC)n & $\begin{array}{l}\text { CCCATAATACTGTCGATGAGCA } \\
\text { GAATGTAGGGAAACATGCATGA }\end{array}$ & $239-243$ & 4 & 0.427 & 0.393 & No \\
\hline 11 & STI046 & $(\mathrm{GAT}) \mathrm{n}$ & $\begin{array}{l}\text { CAGAGGATGCTGATGGACCT } \\
\text { GGAGCAGTTGAGGGCTTCTT }\end{array}$ & $200-218$ & 7 & 0.776 & 0.746 & No \\
\hline 12 & STI031 & (TCA)n & $\begin{array}{l}\text { CAGAGGATGCTGATGGACCT } \\
\text { GGAGCAGTTGAGGGCTTCTT }\end{array}$ & $140-156$ & 8 & 0.805 & 0.783 & No \\
\hline 13 & STM0030 & $\begin{array}{l}\text { Compound } \\
(\mathrm{GT} / \mathrm{GC})(\mathrm{GT}) 8\end{array}$ & $\begin{array}{l}\text { AGAGATCGATGTAAAACAC } \\
\text { GTGTGGCATTTTGATGGATT }\end{array}$ & $153-178$ & 5 & 0.549 & 0.506 & No \\
\hline 14 & STM5121 & (TGT)n & $\begin{array}{l}\text { CACCGGAATAAGCGGATCT } \\
\text { TCTTCCCTTCCATTTGTCA }\end{array}$ & 306-309 & 2 & 0.124 & 0.117 & Yes \\
\hline 15 & STM0019a & $\begin{array}{l}\text { (AT)7(GT)10(AT)4 } \\
(\mathrm{GT}) 5(\mathrm{GC}) 4(\mathrm{GT}) 4\end{array}$ & $\begin{array}{l}\text { AATAGGTGTACTGACTCTCAATG } \\
\text { TTGAAGTAAAAGTCCTAGTATGTG }\end{array}$ & $210-225$ & 5 & 0.504 & 0.478 & Yes \\
\hline 16 & STPoA58 & (TA) 13 & $\begin{array}{l}\text { TTGATGAAAGGAATGCAGCTTGTG } \\
\text { ACGTTAAAGAAGTGAGAGTACGAC }\end{array}$ & $246-250$ & 3 & 0.328 & 0.313 & Yes \\
\hline
\end{tabular}


Table 4. Jaccard's similarity matrix for 20 potato genotypes analysed using 17 SSR markers

\begin{tabular}{|c|c|c|c|c|c|c|c|c|c|c|c|c|c|c|c|c|c|c|c|c|}
\hline & $\mathrm{CR}$ & $\mathrm{KB}$ & $\mathrm{K} 1$ & $\mathrm{KL}$ & KG & MD & MB & N1 & N5 & 19.1 & 9.41 & $\mathrm{PT}$ & RG & $\mathrm{RS}$ & RT & $\mathrm{SH}$ & $\mathrm{VC}$ & 6.1 & 4.1 & 8.1 \\
\hline \multicolumn{21}{|l|}{ Cruza } \\
\hline Kabera & 4.7 & & & & & & & & & & & & & & & & & & & \\
\hline Kachpot1 & 5.5 & 4.8 & & & & & & & & & & & & & & & & & & \\
\hline Kimuli & 4.3 & 3.6 & 3.9 & & & & & & & & & & & & & & & & & \\
\hline Kinigi & 2.8 & 5.1 & 4.7 & 4.0 & & & & & & & & & & & & & & & & \\
\hline Mabondo & 5.7 & 5.4 & 2.9 & 4.6 & 5.0 & & & & & & & & & & & & & & & \\
\hline Mbumbamagara & 4.5 & 4.2 & 3.7 & 3.0 & 4.4 & 4.1 & & & & & & & & & & & & & & \\
\hline Nakpot1 & 4.5 & 4.8 & 3.4 & 4.1 & 4.2 & 2.7 & 3.6 & & & & & & & & & & & & & \\
\hline Nakpot5 & 3.7 & 3.5 & 4.5 & 3.5 & 3.9 & 4.9 & 3.7 & 4.4 & & & & & & & & & & & & \\
\hline NKRK19.10 & 4.5 & 3.6 & 4.7 & 4.1 & 4.4 & 5.1 & 4.6 & 4.9 & 2.6 & & & & & & & & & & & \\
\hline NKRI59.41 & 3.1 & 4.2 & 5.3 & 4.8 & 3.6 & 5.1 & 4.6 & 4.0 & 2.9 & 3.6 & & & & & & & & & & \\
\hline Petero & 3.1 & 4.0 & 4.0 & 3.5 & 3.2 & 4.4 & 4.0 & 4.3 & 3.5 & 3.8 & 3.9 & & & & & & & & & \\
\hline Rwangume & 3.8 & 4.3 & 5.2 & 4.4 & 4.2 & 5.1 & 4.1 & 4.6 & 3.4 & 3.6 & 3.5 & 3.6 & & & & & & & & \\
\hline Rwashaki & 3.2 & 4.1 & 3.8 & 3.8 & 3.6 & 3.9 & 3.5 & 3.8 & 3.3 & 3.4 & 3.2 & 1.9 & 2.5 & & & & & & & \\
\hline Rutuku & 3.8 & 3.8 & 4.3 & 3.1 & 3.5 & 5.0 & 4.1 & 4.4 & 2.5 & 3.2 & 3.9 & 3.2 & 2.6 & 3.1 & & & & & & \\
\hline Shutama & 4.2 & 3.6 & 4.6 & 3.9 & 4.0 & 5.3 & 3.8 & 4.7 & 3.5 & 4.3 & 4.0 & 4.4 & 5.3 & 4.7 & 4.4 & & & & & \\
\hline Victoria & 3.0 & 3.8 & 5.2 & 4.2 & 2.7 & 5.2 & 4.2 & 4.3 & 3.3 & 3.9 & 2.3 & 3.5 & 3.9 & 3.6 & 4.0 & 3.0 & & & & \\
\hline 396026.103 & 5.1 & 3.3 & 5.1 & 4.0 & 4.8 & 5.2 & 4.8 & 5.2 & 3.3 & 3.1 & 4.1 & 4.1 & 3.8 & 4.0 & 3.5 & 4.3 & 3.8 & & & \\
\hline 396034.103 & 5.3 & 3.3 & 5.2 & 4.2 & 5.1 & 5.3 & 4.7 & 5.3 & 3.5 & 3.6 & 4.2 & 4.2 & 3.9 & 4.1 & 3.7 & 4.2 & 4.0 & 1.0 & & \\
\hline 396038.107 & 4.4 & 3.2 & 4.4 & 1.9 & 4.5 & 4.8 & 3.6 & 4.4 & 2.9 & 3.4 & 4.1 & 3.8 & 4.6 & 3.8 & 3.5 & 3.8 & 3.9 & 3.8 & 3.9 & \\
\hline
\end{tabular}

Note. $\mathrm{CR}=$ Cruza; $\mathrm{KB}=$ Kabera; $\mathrm{K} 1=$ Kachpot1; $\mathrm{KL}=$ Kimuli; $\mathrm{KG}=$ Kinigi; $\mathrm{MD}=$ Mabondo; $\mathrm{MB}=$ Mbumbamagara; $\mathrm{N} 1=$ Nakpot1; $\mathrm{N} 5=$ Nakpot5; $19.1=$ NKRK19.10; $9.41=$ NKRI59.41; PT $=$ Petero; $\mathrm{RG}=$ Rwangume; RS = Rwashaki; RT = Rutuku; $\mathrm{SH}=$ Shutama; VC = Victoria, 6.1 = 396026.103, 4.1 = 396034.103; $8.1=396038.107$.

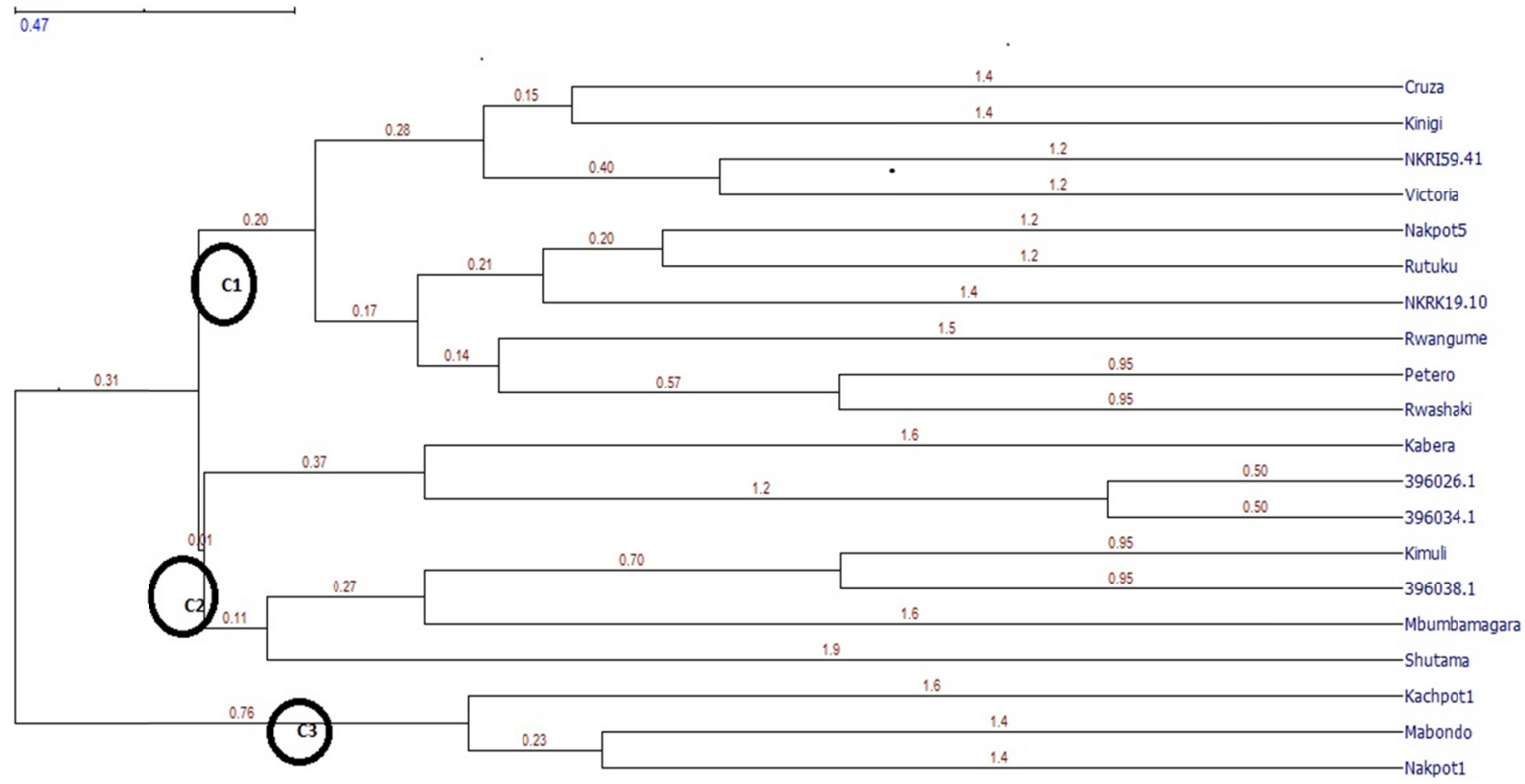

Figure 1. Dendogram showing genetic relationship among 20 potato clones obtained using 16 SSR markers generated by UPGMA. The three clusters identified are $\mathrm{C} 1, \mathrm{C} 2$ and $\mathrm{C} 3$ 


\section{Discussion}

The 64 number of alleles revealed by microsatellites in this present study and the number of alleles per locus (range 2 to 8) was low compared to earlier studies. For instance, Sharma and Nandineni (2014) obtained 139 alleles while alleles per locus ranged from 6 to 11 with 44 potato genotypes using 17 SSR markers. Ghislain et al (2009) detected 137 alleles using 24 SSR markers on 742 potato genotypes with the range of 3 to 9 alleles per locus. In both studies more potato genotypes were used with almost the same primers. However, Muthoni et al. (2014) identified 160 alleles and the SSR loci ranged from 2 to 14 with 20 potato clones using 24 SSR markers. In this study more alleles were identified with relatively the same number of markers and genotypes. On the other hand, Solano et al. (2103) recorded 64 alleles using seven SSRs and 40 potato clones while Muhinyuza et al. (2015) observed 84 alleles with 13 SSR markers and 18 genotypes. It can thus be observed that other than the number of markers and genotypes used, other factors contribute to the total number of alleles detected. The lower total number of alleles in this study can be attributed to the high percentage of null alleles in some genotypes where several markers failed to produce detectable variation.

However, several markers performed differently in the current study compared to previous ones. For instance ST1046 (0.776), relatively higher PIC values were observed by Rocha (2010); Muthoni et al. (2014); and Muhinyuza et al. (2015) with values of $0.970,0.836$ and 0.842 respectively. Some markers used in this study had extremely low PIC values from those found in previous studies that is ST10023 had 0.795 and 0.813; STM5121 had 0.374; STM1049 had 0.784 while STM0037 had 0.683 (Muthoni et al., 2014; Ghislain et al., 2009). In other studies, STI0030 had 0.76 (Hirut, 2015) while STI0036 had 0.839 (Muthoni et al., 2014). The low PIC values in this study could be explained by the fact that most of the genotypes used were not so closely related yet microsatellites are particularly useful for closely related genetic materials. Furthermore, the differing laboratory procedures could have resulted into the observed variances in PIC values.

Significant variation of genetic distance among genotypes showed the presence of genetic diversity among them. Genotypes from CIP tended to be clustered together suggesting a common ancestry. Farmer's varieties can be used as parents in the breeding programme given their less relatedness while clones 396026.103 and 396034.103 may not be crossed as this may result into reduced genetic variation and in breeding depression in their progenies. Cruza is an old variety with the highest genetic distance; less likely to be related to other genotypes and thus can be used as parent in the breeding program.

\section{Conclusion}

The study determined the pattern and level of genetic diversity among the selected 20 tetraploid potato genotypes using 16 SSR markers to identify suitable parents for breeding purposes. The microsatellites were useful and revealed considerable genetic variation among genotypes which can be exploited for possible crop improvement. The genotypes were clustered into three and the following were selected for use in the crop improvement programme: Kinigi, Rwangume and NKRI59.41 from cluster 1; 396034.103, 396038.107 and Kimuri from cluster 2; and Nakpot1 from cluster 3.

\section{Acknowledgements}

The Alliance for a Green Revolution in Africa (AGRA) is sincerely thanked for funding this study. Due thanks to the National Agricultural Research Organisation (NARO) for granting study leave to the first author.

\section{References}

Acquaah, G. (2007). Principles of plant genetics and breeding. Blackwell, UK.

Acquaah, G. (2012). Principles of plant genetics and breeding (2nd ed.). Wiley-Blackwell. https://doi.org/ $10.1002 / 9781118313718$

Anderberg, M. R. (1973). Cluster analysis for applications. Academic press, New York.

Berloo, V. R. (2008). GGT 2.0: Versatile software for visualization and analysis of genetic data. Heredity, 99, 232-6. https://doi.org/10.1093/jhered/esm109

Coombs, J. J., Frank, L. M., \& Douches, D. S. (2004). An applied fingerprinting system for cultivated potato using simple sequence repeats. Ame J of Pot Res, 81, 243-250. https://doi.org/10.1007/BF02871765

Ghislain, M., Núnez, J., Rosario Herrera, M., Pignataro, J., Guzman, F., \& Bonierbale, M. (2009). Robust and highly informative microsatellite-based genetic identity kit for potato. Mol Breeding, 23, 377-388. https://doi.org/10.1007/s11032-008-9240-0 
Ghislain, M., Spooner, D., Rodríguez, F., Villamón, F., Nunez, J., \& Vásquez, C. (2004). Selection of highly informative and user-friendly microsatellites (SSRs) for genotyping of cultivated potato. Theor and Appl Gen, 108, 881-890. https://doi.org/10.1007/s00122-003-1494-7

Gopal, J. (2014). Heterosis breeding in potato. Agr Res, 3, 204-217. https://doi.org/10.1007/s40003-014-0120-z

Gopal, J. (2015). Challenges and way-forward in selection of superior parents, crosses and clones in potato breeding. Potato Res, 58, 165-188. https://doi.org/10.1007/s11540-015-9292-6

Gopal, J., \& Minocha, J. L. (1997). Genetic divergence for cross prediction in potato. Euphytica, 97, $269-275$. https://doi.org/10.1023/A:1003076207221

Govindaraj, M., Vetriventhan, M., \& Srinivasan, M. (2015). Importance of genetic diversity assessment in crop plants and its recent advances: An overview of its analytical perspectives. Genet Res International, 2015, 431487. https://doi.org/10.1155/2015/431487

Hirut, G. B. (2015). Genetic analyses of drought tolerance and resistance to late blight among potato genotypes (PhD Thesis, University of KwaZulu-Natal, South Africa).

Mbogori, M., Kimani, M., Kuria, A., Lagat, M., \& Danson, J. (2006). Optimization of FTA technology for large scale plant DNA isolation for use in marker assisted selection. Afri J Biotech, 5, 693-696.

Muhinyuza, J. B., Shimelis, H., Melis, R., Sibiya, J., Gahakwa, D., \& Nzaramba, M. N. (2015). Assessment of genetic relationship among potato genotypes grown in Rwanda using SSR markers. Aust J Crop Sci, 9, 696-700.

Muthoni, J., Shimelis, H., \& Melis, R. (2014). Study of genetic relationship among Kenyan cultivated potato clones using SSR markers. Aust J Crop Sci, 8, 502-508.

Park, T. H., Vleeshouwers, V., Jacobsen, E., Van Der Vossen, E., \& Visser, R. (2009). Molecular breeding for resistance to Phytophthora infestans (Mont.) de Bary in potato (Solanum tuberosum L.): A perspective of cisgenesis. Plant Breeding, 128, 109-117. https://doi.org/10.1111/j.1439-0523.2008.01619.x

Payne, R. W.., Murray, D. A., Harding, S. A., Baird, D. B., \& Soutar, D. M. (2011). GenStat for windows (14th ed.). Introduction. Hemel Hempstead: VSN International, UK.

Rocha, E. A., Paiva, L. V., Carvalho, H. H., \& Guimarães, C. T. (2010). Molecular characterization and genetic diversity of potato cultivars using SSR and RAPD markers. Crop Breed and Appl Biotech, 10, 204-210. https://doi.org/10.1590/S1984-70332010000300004

Sharma, V., \& Nandineni, M. R. (2014). Assessment of genetic diversity among Indian potato (Solanum tuberosum L.) collection using microsatellite and retrotransposon based marker systems. Mol Phylogenet Evol, 73, 10-17. https://doi.org/10.1016/j.ympev.2014.01.003

Solano, J., Mathias, M., Esnault, F., \& Brabant, P. (2013). Genetic diversity among native varieties and commercial cultivars of Solanum tuberosum ssp. Tuberosum L. present in Chile. Electron J Biotechn, 16(6), 14. https://doi.org/10.2225/vol16-issue6-fulltext-15

Sun, G., Wang-Pruski, G., Mayich, M., \& De Jong, H. (2003). RAPD and pedigree-based genetic diversity estimates in cultivated diploid potato hybrids. Theor and Appl Gen, 107, 110-115. https://doi.org/10.1007/ s00122-003-1215-2

\section{Copyrights}

Copyright for this article is retained by the author(s), with first publication rights granted to the journal.

This is an open-access article distributed under the terms and conditions of the Creative Commons Attribution license (http://creativecommons.org/licenses/by/4.0/). 